\title{
Integrated Design in Sustainable Architectural Education
}

\author{
Shaojie Zhang $^{1}$ Tieqiao Xiao $^{2}$ \\ ${ }^{1,2}$ Department of Architecture \& Urban Planning, \\ Anhui University of Architecture, Hefei, China
}

\begin{abstract}
Green buildings and sustainable design have become the points architects are concerned about. At the same time, a lack of collaboration with other design disciplines is a problem encountered by many architecture designers. In such a situation, some architects promote a method of integrated design, which can fix the gap in interdisciplinary collaboration in the process of construction and operation of building. In this article, the authors introduced the integrated design and analyzed it in architectural education as well as provide case studies to offer specific evidence.
\end{abstract}

Keywords: Integrated Design; Architectural Education; Green building

\section{Definition of Integrated Design}

What is design? The nature of design as an integrative discipline places it at the intersection of several large fields. In one dimension, design is a field of thinking and pure research. In another, it is a field of practice and applied research. When applications are used to solve specific problems in a specific setting, it is a field of clinical research [1]. Therefore, design does not only have relationship with a given designer or architect, but also has relationship with other fields, such as mechanical engineering, material, management, and so on. In that case, only integrated design can help architects to address the problems of gaps between different fields. With integrated design, it is necessary to consider each discipline as a unified whole and use them as problemsolving tools.

Integrated design is a collaborative method for designing buildings that emphasizes the development of a holistic design [2]. In other words, integrated design means standing at the peak, dominating the whole procedure and controlling everything. Because the process of integrated design takes whole parts of building into account, the production of integrated design can be guaranteed more efficient, energy-saving, less toxic, and comfortable building which considers the needs of all members in society.

\section{Integrated Design in Sustainable Architectural Education}

\subsection{Why is integrated design needed in architectural education}

We know that integrated design can fix the gaps among each discipline up. Introducing the concept of integrated design in education can help students to adapt to the real projects after graduation and communicate with their team members from any other fields well. However, the approach of single discipline teaching is limited; the greatest challenges facing architecture, engineering, and construction (AEC) educators today are effectively integrating interdisciplinary aspects into 
their curriculum. The AEC professions have the opportunity to engage with each other to create more efficient frameworks for delivering buildings. These frameworks include integrated collaborative; design teams; effective and immediate communication and decision making; and highly efficient fabrication, delivery, and construction systems [3].

\subsection{Case study 1: Student team in CAL POLY}

To address the interdisciplinary shortcomings in traditional architecture, engineering, and construction curricula, two faculty members at Cal Poly suggest the strategy in linking curricula to practice and increasing communication between departments across their college. They held a class, which is structured around the concept that the instructors are also an integrated project team. This includes instructors from three disciplines: architecture, structural engineering, and construction management. Also, they combine this with a mix of students from these disciplines collaborating on a series of projects during the term.

The class is a hybrid teaching environment using both lectures and project based learning to explore the numerous topics related to the building skin. Three main components were developed to achieve the learning objectives:

1) Lectures and roundtables

2) The envelope analysis project

3) The envelope design project

During the first half of the term, a series of individual lectures and group the instructors presented round table discussions. Each instructor presented detailed material about his individual discipline's relationship to building envelopes, which created a dynamic learning environment, fielding questions from the other instructors and the students.
The second half of the term is devoted to the envelope design project. Information is given to student teams for the development of a new building envelope with a scope limited by some parameters. The teams are asked to prepare a design, engineer, and provide construction management skills for installing the envelope system and provide documentation of the process. The students are required to present their designs in three-dimensional graphic form, a calculated structural analysis with appropriate detailing, costing breakdown, and a buildibility analysis that describes procurement, scheduling, and installation.

As part of a final evaluation of the students' absorption of the material, we included a final exam with essay questions. The questions varied from topics germane to the issue of integrated project teams and building envelopes to a self-reflective question for the individual student about their experiences in the class. This critical post-project reflection by the students gave the instructors direct feedback about their learning experience and an often-candid assessment of their interactions as members of the integrated student teams.

In the end, the authors of this article summarize the final work accomplished by students. Their goal of providing a hybrid-learning framework to introduce integrated practice issues using an integrated instructor team has created an effective and dynamic learning environment. While the lecture topics were carefully coordinated through the term to be able to cover appropriate material, the round-table discussions with full instructor team attendance became an exercise on "thinking on your feet" in a similar way to real world situations. On the other hand, the student feedback on the class has been very positive. Because of the close collaboration on the student 
teams, the students developed respect for their peers and the other professions.

As I see, the whole planning of the curriculum is reasonable and logical. This class has also promoted the communication between departments and instructors. At the same time, the students in architecture, engineering, and construction management can get the knowledge from each other's field, which is a positive experience for their future performance in profession.

At the same time, this curriculum can help the students in those three disciplines know their own roles and responsibility in teamwork. However, this case study is not perfect; it still need to be improved in some places. For one thing, they should introduce building information modeling as a learning tool. The desire was to use this emerging technology of BIM as a method for creating a shared digital model that all the disciplines could use through the design process.

\subsection{Case study 2: Ecollaborative in University of Cincinnati}

The Ecollaborative is an interdisciplinary design studio where teams of students from business, industrial design, and environmental studies. Following Raelin's [4] and Loughran's [5] model of using reflective practice as a basis for learning, this course unfolds in three stages: (1) anticipatory reflection through research and learning, contemporaneous reflection through analysis of existing products and the product design and development process, and (3) retrospective reflection that occurs as students maintain a journal about the insights gained through the process.

A studio is a hands-on, immersion experience. Students have their own workspace and are surrounded by the design problem. Faculty members begin as dispensers of information and initial problem characteristics but quickly shift to roles of collaborator and fellow learner. Students and teacher discover solutions together through informal creative interactions as part of the studio's learning community.

All students should be familiarized with these concepts, but those in each discipline should be guided toward a deeper understanding of concepts and skills appropriate to their discipline. Designers focus on skills and concepts correlating to their profession, including design for the environment (DFE), designing for extended producer's responsibility (EPR), resource recovery, and biomimicry. Management students need more understanding of different perspectives on the environmental challenge (a good bibliography was provided by Ryland [6] and working knowledge of alternative business practices and exposure to case studies of companies that promote sustainability (e.g., IKEA, Interfaces, Skandic). Texts such as Russo [7] and Nattrass and Altomare [8] are useful resources. It is best if this information is provided in earlier coursework.

When the course begins, lectures, exercises, or presentations offered by faculty and the corporate sponsor add to this initial familiarization as well as teach specific skills. In the second (contemporaneous reflection) stage, the design and marketing brief developed by the faculty and corporate partner is assigned to the teams. Subsequently, students meet with their teamwork consultant to debrief team process issues. Students are expected to check in (via email) with the consultant each week concerning any issues about team performance. In the process of retrospective reflection (stage 3), students are asked to keep a journal of their performance, team process, ideas, insights, frustrations, and so on. It also 
allows faculty an opportunity to monitor the team process and to help coach students on effective team processes. The overall course ends with a final presentation and critique of the proposed redesign of the product. At the time, revising business and marketing plan is one more opportunity for retrospective reflection [9].

The faculty who delivers this course thinks that their aim is to help students cross the disciplinary boundaries. Students come to understand the institutional and ideological authority expressed in those theories and how traditional faculty-student relationships reinforce this authority. Surely, in this course, they reach their aim and the students get special experience from interdisciplinary collaboration.

\section{Conclusion}

From these two case studies above, we know that the most important role of education is to shape the trajectory of exploration after graduation, thus contributing to the future of the profession. The projects' aim is to introduce the conception of interdisciplinary collaboration to students. These students are not outsiders who sit in the classroom and be taught by teachers with tedious theories but as participants who can experience the process of integrated design and directly know the advantages of that. As Cheng [10] says, "Changes in the profession of architecture inevitably place pressure on architectural education." The innovation of architecture must reflect on the field of education. The students are the right ones who will be the future architects; only they know how to utilize integrated design in architecture, the aim of sustainable building or green building that can be achieved in the future.
The students and faculty always get positive experiences and knowledge from interdisciplinary collaboration. After training in such curriculums, students can understand the operation procedure of a whole project and find their role in a team, which is very helpful for students' profession in the future. There is an urgent and immediate need for architectural education to prepare future practitioners who will catalyze the improvement of architecture. A new, integrated curriculum might have to adjust some of its traditional assumptions in support of new priorities, including the need to produce and disseminate research and knowledge at the intersection of architecture, construction, planning, law, manufacturing, and real estate, among other vocabularies.

Other than a few pioneering professional practice and construction courses, recent innovations in architectural education have largely focused on formal skills needed to succeed in design. The design studio has frequently succumbed to the seduction of new forms or reinterpreting established formal compositional principles. For students fluent at generating form in a variety of media, possibilities raised by new production methods are largely unexplored; ephemeral factors such as time or light remain invisible in the design process; and the underlying logic of the representation software is poorly understood. This essay seeks to establish principles for a holistic reinvention of architectural design curriculum - a curriculum that can produce practitioners who will capitalize on emerging opportunities to truly transform both design and construction.

A good collaboration is a positive start for any construction project. A sustainable building needs several aspects of professional workers, except for architects, mechanical engineers, 
electrical engineers, structural engineers, and some consultants in business and the environment are needed. Most times, vernacular situations should be considered, too, if it is an international project. In a word, we have to remember that a fundamental tenet of true sustainability is the integration of all building systems within themselves as well as with the external economic and environmental realities of the project.

On the other hand, building information modeling (BIM) can be used to refine the integrated design. When the entire design team is able to share and influence a three-dimensional virtual model in an effort to gauge the impact of each other's work on the whole building, true integration all of a sudden becomes more real and compelling. But this next generation is yet embryonic in the BIM world of today. Some pieces have already been born. Structural and mechanical models can now interact with architectural models, for example, for purposes of coordination. System coordination can occur more accurately and fluidly within this virtual model rather than the more expensive alternative of on-site field coordination. Still untapped, however, is the capacity of the software to perform all the aspects of modeling and analysis critical for achieving true sustainable design. Instead, versions of the BIM model are recreated in separate virtual worlds (or software), which produce information that is then translated back to the design team for possible adjustments to the design. Further still, information regarding the environmental impact of material and system choices is still collected and integrated in the draconian fashion of catalog and manual referencing as they are being integrated into the model. Alternatively, with BIM, these parameters could easily be embedded within the model itself.

\section{References}

[1] Friedman, Ken. (2003). Theory Construction in Design Research: Criteria: Approaches, and Methods. Design Studies, v24,no.26.

[2] Keeler, Marian. (2009). Fundamentals of Integrated Design for Sustainable Building. Wiley.

[3] Doerfler, James,. \& Dong, Kevin. (2009). Teaching Integrated Practice in a Cross-Disciplinary Curriculum after Two Years.

[4] Raelin, J. A. (2001). Public reflection as the basis of learning. Management Learning, 32(1), 11-30.

[5] Loughran, J. J. (1996). Developing reflective practice: Learning about teaching and learning through modelling. London: Falmer.

[6] Ryland, E.K. (1998). Greening business education: Teaching the paradigm. Journal of Management Education, 22(3), 320-343.

[7] Russo, M. V. (1999). Environmental management. Boston: Houghton Mifflin.

[8] Nattrass, B., \& Altomare, M. (1999). The natural step for business. Gabriola Island, BC: New Society Publishers.

[9] Welsh, M. Ann.,\& Murray, Dale L. (2003). The ecollaborative: teaching sustainability through critical pedagogy. Journal of Management Education.27, 220.

[10] Cheng, Renée (2005), Suggestions for an Integrative Education, Report on integrated practice. Washington, DC: American Institute of Architect 